\title{
Resíduos orgânicos para o controle das doenças do feijoeiro causadas por Sclerotium rolfsii
}

\author{
Organic residues for the control of bean diseases caused by Sclerotium \\ rolfsii
}

\author{
Vanessa Nataline Tomazeli ${ }^{\prime(*)}$ \\ Idalmir Santos ${ }^{2}$ \\ Rafael Gustavo Ferreira Morales ${ }^{3}$
}

\section{Resumo}

A incorporação de matéria orgânica ao solo tem se mostrado eficiente para o controle de alguns fitopatógenos habitantes do solo. O efeito dessa prática agrícola, principalmente sobre patógenos formadores de escleródios, como Sclerotium rolfsii, ainda não é completamente conhecido. O experimento, em dois anos de cultivo, foi conduzido no campo experimental da Universidade Tecnológica Federal do Paraná (UTFPR), em parcelas de um metro quadrado, contendo solo infestado com 100 g por parcela do substrato (arroz em casca) contendo o patógeno. Os tratamentos foram chorume de suínos, cama de aviário, repolho triturado e testemunha, apenas patógeno, com quatro repetições. A semeadura de 80 sementes de feijão por parcela foi efetuada após uma semana da aplicação dos respectivos tratamentos. A intensidade da doença foi avaliada pela emergência, tombamento, incidência e severidade da doença. Os fatores como atividade microbiana, níveis de fertilidade do solo, número e sobrevivência de escleródios e massa das plantas fresca foram avaliados no fim do cultivo. O composto orgânico, cama de aviário, apresentou uma maior redução da incidência e a severidade da doença e, consequentemente, o tombamento de plântulas. Porém, apesar de reduzir a intensidade da doença, não houve aumento da emergência nos dois primeiros cultivos. Esse efeito benéfico da cama-de-aviário (CA) pode estar associado ao aumento da matéria orgânica do solo e, consequentemente, da atividade microbiana, principal responsável pela redução da patogenicidade do fungo. Como consequência ao impacto provocado pela incorporação de CA ao solo, houve aumento da massa fresca da planta e

I MSc.; Engenheira Agrônoma; Técnica Ambiental na Secretaria Estadual de Meio Ambiente do Rio Grande do Sul; Endereço: Rua Ignácio Jordani, 1983, CEP: 99.560-000, Sarandi, Rio Grande do Sul, Brasil; E-mail: vanetomazeli@hotmail.com (*) Autora para correspondência.

2 Dr.; Engenheiro Agrônomo; Professor da Universidade Tecnológica Federal do Paraná, UFTPR; E-mail: idalmir@utfpr.edu.br

3 MSc.; Engenheiro Agrônomo; Doutorando em Fitotecnia na Universidade Federal de Lavras, UFLA; E-mail: moralescefet@yahoo.com.br

Recebido para publicação em I8/02/20II e aceito em I I/04/20II

\begin{tabular}{llllll}
\hline Ambiência Guarapuava (PR) v.7 n.I & p. 65 - $74 \quad$ Jan./Abr. 20II & ISSN 1808 - 025 I
\end{tabular}

DOI: $10.5777 /$ ambiencia.2011.01.04 
redução do número de escleródios. Assim, com base nesses resultados, pode-se concluir que a CA apresenta efeito supressivo sobre as doenças causadas por $S$. rolfsii.

Palavras-chave: matéria orgânica; solo supressivo; atividade microbiana.

\section{Abstract}

Organic matter incorporation into the soil has proved effective for the control of some soil-borne plant pathogens. The effect of this agricultural practice, especially on sclerotium-forming pathogens such as Sclerotium rolfsii, is not yet completely understood. The experiment, conducted over a two-year cultivation period, was carried out at UTFPR's experimental field in one-square meter plots containing soil infested with $100 \mathrm{~g}$ per plot of the substrate (unhulled rice) containing the pathogen. Treatments consisted of liquid swine manure, poultry bedding (PB), ground cabbage, and a control, only pathogen, with four replicates. Eighty bean seeds were sown per plot one week after the treatments were applied. Disease intensity was evaluated based on plantlet emergence, damping-off, incidence, and severity. Factors such as microbial activity, soil fertility levels, number and survival of sclerodia, and plant green matter were evaluated at the end of the cropping cycle. Poultry bed incorporation into the soil showed significant results in reducing intensity of the disease and the pathogen's inoculum, in both cropping seasons. The organic compound, poultry bedding, had the greatest reduction in incidence and severity of disease and the damping-off. However, although reducing the amount of disease, no increase in emergency first two crops. This beneficial effect of PB may be associated with increased soil organic matter and thus microbial activity, responsible for reducing the pathogenicity of the fungus. As a result of the impact caused by the incorporation of $\mathrm{PB}$ to the ground, there was an increase of fresh weight of plant and reducing the number of sclerodia. So based on these results, we can conclude that PB has a suppressive effect on diseases caused by $S$. rolfsii.

Key words: organic matter; suppressive soil; microbial activity.

\section{Introdução}

O feijoeiro (Phaseolus vulgaris L.) está sujeito a um grande número de doenças que podem tomar um caráter epidêmico. Dentre estas, pode-se citar a murcha de Sclerotium causada pelo fungo Sclerotium rolfsii Sacc. Quando infesta o solo, esse patógeno provoca grandes perdas na produtividade, principalmente devido ao tombamento de pré e pós-emergência (BIANCHINI et al., 1997). Além do mais, o patógeno é de difícil controle, podendo seus escleródios sobreviver no solo por vários anos (BUENO et al., 2004).

As atuais estratégias de controle de patógenos habitantes de solo, tais como, tratamento químico das sementes, resistência genética e rotação de culturas, auxiliam na redução de inóculo do fitopatógeno, mas 
apresentam baixa eficiência. A busca de novas alternativas de controle, como a incorporação de resíduos orgânicos ao solo, apresentam diversos resultados de sucesso (MORALES et al., 2007).

A utilização de matéria orgânica apresenta, em alguns casos, efeitos supressivos sobre patógenos de solo (HOITINK; FAHY, 1986). Os compostos orgânicos podem atuar nos fitopatógenos diretamente pela produção de compostos químicos, como ácidos graxos voláteis, ácido nitroso, amônia e isotiocianatos, ou indiretamente favorecendo o aumento da população dos antagonistas (GAMLIEL; STAPLETON, 1993; LAZAROVITZ, 2001). Robbs (1991) observou que escleródios de $S$. rolfsii eram destruídos meses após a incorporação de resíduos orgânicos ao solo. Segundo o autor, esse fato ocorria devido à ação de microrganismos antagonistas não patogênicos. Lazarovits (2001) constatou que a aplicação de chorume de suínos (CS) reduziu, por três anos consecutivos, as doenças causadas por Verticillium dabliae Kleb. Ghini et al. (2002) observaram significativo controle do tombamento de plântulas de pepino, causado por Pythium spp. Pringsh, com a incorporação de cama de aviário ao solo.

É crescente a demanda por um modelo sustentável de produção, priorizando-se a redução da utilização de produtos químicos. Entretanto, para alcançar tal êxito, é preciso conhecer todas as variáveis das novas alternativas de controle. Assim, o presente trabalho teve como objetivo avaliar o efeito de diferentes resíduos orgânicos sobre as doenças causadas por $S$. rolfsii, em feijoeiro.

\section{Material e Métodos}

O trabalho foi realizado no campo experimental da UTFPR, Campus de Pato
Branco, Brasil, latitude $26^{\circ} 07^{\prime}$ Sul, longitude 52 ० $41^{\prime}$ Oeste e altitude de $700 \mathrm{~m}$.

Os efeitos dos resíduos orgânicos sobre $S$. rolfsii foram avaliados durante dois anos, em parcelas de $1 \mathrm{~m}^{2}$ contendo solo infestado, vinte dias antes da aplicação dos tratamentos, com $100 \mathrm{~g}$ por parcela do substrato arroz em casca. Para tanto, um isolado de $S$. rolfsii obtido no laboratório de Fitopatologia da UTFPR foi incubado por dez dias em placas de Petri contendo meio de BSA (batata-sacarose-ágar). O fungo foi multiplicado em $100 \mathrm{~g}$ de arroz com casca e $150 \mathrm{ml}$ de água destilada em frascos de $1 \mathrm{~L}$ de capacidade. $\mathrm{O}$ substrato foi previamente autoclavado por uma hora, numa temperatura de aproximadamente 120 ${ }^{\circ} \mathrm{C}$, durante dois dias consecutivos. Foram colocados 10 discos de BSA de $6 \mathrm{~mm}$ de diâmetro contendo o fungo em cada frasco. O substrato foi acondicionado em sala de crescimento durante um período de dez dias, sob temperatura de $25^{\circ} \mathrm{C} \pm 2$ e fotoperíodo de doze horas.

$\mathrm{O}$ experimento foi dividido em duas épocas, com dois cultivos no primeiro ano, sendo estes denominados de primeiro e segundo cultivos, e um cultivo no segundo ano do experimento, denominado de terceiro cultivo.

Um cultivo teste foi realizado antes da primeira aplicação dos tratamentos para verificar a presença e a homogeneidade de ocorrência da doença nas parcelas. Para tanto, oitenta sementes de feijão foram semeadas em cada parcela, avaliando-se a emergência e o tombamento das plântulas.

O experimento foi montado em blocos casualizados com quatro repetições por tratamento. Os tratamentos constituíram-se na incorporação de três compostos orgânicos e uma testemunha sem incorporação de 
resíduos. Os compostos utilizados foram: chorume de suínos (CS) na dose de $60 \mathrm{~m}^{3}$ $\mathrm{ha}^{-1}$; cama-de-aviário (CA) na dose de 30 ton $\mathrm{ha}^{-1}$; e repolho triturado (RT), na dose de 40 ton $\mathrm{ha}^{-1}$. O CS foi obtido da estação experimental do Instituto Agronômico do Paraná (IAPAR), apresentando $21 \%$ de massa seca; $\mathrm{pH} 9,17 ; 2,1 \%$ de fósforo; $1,5 \%$ de potássio e $1,4 \%$ de $\mathrm{N}$ total. A CA foi adquirida na empresa Frango Seva Ltda., e possuía $\mathrm{pH}$ de 8,4 e $83 \%$ de massa seca; $3,5 \%$ de fósforo; $2,8 \%$ de potássio e 3,2\% de $\mathrm{N}$ total. No tratamento com repolho foi utilizada a espécie Brassica oleracea var. capitata, que possuía 9\% de massa seca; 0,5\% de fósforo; $2,5 \%$ de potássio e 1,6 \% de $\mathrm{N}$ total.

Os compostos foram incorporados até a profundidade de $10 \mathrm{~cm}$ e todas as parcelas foram molhadas até a saturação do solo. Antes da semeadura das sementes de feijão foram coletados aproximadamente $500 \mathrm{~g}$ de solo, em seis pontos de cada parcela, para as avaliações da atividade microbiana e fertilidade do solo, esta última, realizada conforme metodologia descrita por Pavan e Miyazawa (1991). A semeadura de 80 sementes de feijão por parcela, cultivar UTF1 com $94 \%$ de poder germinativo, adquirida do melhoramento genético da UTFPR, foi realizada uma semana após a incorporação da matéria orgânica, no primeiro e segundo ano de cultivo. No terceiro cultivo, não foi realizada a aplicação dos respectivos tratamentos pré-estabelecidos no estudo, avaliando-se apenas o efeito residual dos tratamentos.

A intensidade da doença foi avaliada considerando-se a emergência e o estande final de plantas e pela incidência e severidade das doenças. A avaliação da emergência e estande final foi realizada contando-se o número de plantas emergidas após doze dias da semeadura e o total de plantas remanescentes após 24 dias. Para avaliação de incidência foi considerada a porcentagem de plantas com sintomas visíveis da doença, em relação às plantas sadias. Para severidade foi considerada a porcentagem de tecido lesionado no colo da planta, com base na escala diagramática para podridões radiculares do feijoeiro, elaborada por Schoonhoven e Pastor-Corrales (1987). Antes das avaliações de severidade, foi feita a identificação e a confirmação da doença causada por $S$. rolfsii, tendo em vista que as estruturas do fungo foram visualizadas nos tecidos das sementes que não germinaram e das plântulas que não emergiram do solo ou tombaram após a emergência. $\mathrm{O}$ patógeno foi, também, isolado dos tecidos do colo das plantas submetidas à avaliação da severidade, sendo feita a identificação do patógeno com auxílio de um microscópio óptico.

Após as avaliações de incidência e severidade da doença, fez-se a pesagem das plantas e o resultado foi dividido pelo estande final, obtendo-se a massa fresca por planta.

Para a avaliação do desprendimento de $\mathrm{CO}_{2}$ foram coletadas amostras, em seis pontos de cada parcela, as quais foram homogeneizadas e peneiradas (4 mm). Em seguida, $100 \mathrm{~g}$ de solo por parcela foram incubados em recipientes hermeticamente fechados, com volume de $2 \mathrm{~L}$, contendo no interior uma tampa de uma placa de Petri invertida onde foram adicionados $10 \mathrm{~mL}$ de $\mathrm{KOH}(0,5 \mathrm{~N})$, os quais foram colocados em ambiente escuro, a temperatura $25^{\circ} \mathrm{C} \pm$ 2. Dois outros recipientes, contendo apenas $10 \mathrm{~mL}$ de $\mathrm{KOH}(0,5 \mathrm{~N})$ nas placas de Petri, foram mantidos como controle. Após quinze dias de incubação, o $\mathrm{KOH}$ foi titulado com $\mathrm{HCl}(0,1 \mathrm{~N})$. 
Outro fator avaliado foi o número de esclerócios por parcela e a sobrevivência após o cultivo de feijão. Para isto, coletou-se em seis pontos de cada parcela, na profundidade de 0 - $5 \mathrm{~cm}$, uma amostra de solo totalizando 500 g. Após a homogeneização, retirou-se uma alíquota de $50 \mathrm{~g}$ de cada amostra, a qual foi peneirada com um jogo de cinco peneiras com aberturas de $4,75 \mathrm{~mm}, 2,36$ $\mathrm{mm}, 1,00 \mathrm{~mm}, 0,053 \mathrm{~mm}$ e $0,037 \mathrm{~mm}$, submetida à pressão da água de torneira. As três peneiras, com as menores aberturas, foram mergulhadas em uma bacia branca com água, para retirada e contagem dos esclerócios. Dos esclerócios de cada parcela, utilizou-se uma amostra de dez, escolhidos ao acaso, os quais foram submetidos a uma desinfestação superficial em hipoclorito de sódio a $2 \%$ de cloro ativo, durante três minutos e plaqueados em placas de Petri contendo meio ágar-água. Após 48 horas em sala de crescimento, com temperatura de $25^{\circ} \mathrm{C} \pm 2$, foi avaliada a viabilidade contandose os esclerócios germinados.

Os dados obtidos foram submetidos à análise de variância e as médias foram comparadas pelo teste Duncan a 5\% de probabilidade. Os dados referentes à incidência e severidade foram transformados em "raiz $(X+0,5)$ ", contudo, foram apresentados os dados originais nas tabelas.

\section{Resultados e Discussão}

O tratamento CA no primeiro cultivo apresentou a menor incidência $(47,17 \%)$ e severidade $(10,37 \%)$ da doença (Tabela 1). No segundo cultivo, a CA também apresentou os menores índices de incidência $(40,91 \%)$ e severidade $(8,85 \%)$, sendo que, nesse cultivo, o segundo melhor tratamento foi o CS, com incidência de 49,32\% e severidade de 13,04\% (Tabela 1). No terceiro cultivo, a CA não diferiu dos outros compostos orgânicos, porém os três diferiram do tratamento testemunha. Segundo Rodrigues-Kábana e Calvet (1994), a incorporação de matéria orgânica ao solo pode alterar a composição e a atividade da microbiota, as características físicas e químicas do solo, tornando-o supressivo a diversos fitopatógenos. Segundo Hoiting e Fahy (1986), a redução da incidência da doença pode ainda ser atribuída ao aumento das defesas da planta hospedeira, ou devida à inibição direta da atividade ou crescimento do patógeno.

Os resíduos orgânicos não interferiram na emergência das plantas nos dois primeiros cultivos, contudo, no terceiro cultivo, as parcelas tratadas com CA apresentaram a maior emergência $(78,44 \%)$. Os tratamentos com CS e RT também aumentaram a emergência em relação ao tratamento testemunha, não diferindo entre si (Tabela 1 ). Apesar de não existir diferença na emergência nos dois primeiros cultivos, o tombamento de plantas foi drasticamente reduzido nas parcelas tratadas com CA, chegando a ser nulo no segundo cultivo (Tabela 1 ).

A redução na intensidade da doença observada nos tratamentos com resíduos orgânicos, sobretudo CA no primeiro e segundo ano de cultivo, pode ser atribuída ao aumento da atividade microbiana, avaliada pelo desprendimento de $\mathrm{CO}_{2}$. Este, por sua vez, correlaciona-se com o aumento dos níveis de matéria orgânica, tendo assim um efeito indireto nas relações patógeno-hospedeiro, resultando em possível causa da supressão da doença (LAZAROVITS, 2001). A atividade microbiana do solo é aumentada durante a decomposição da matéria orgânica presente em diversos compostos, 
Tabela I. Avaliação da emergência ( $E)$ e o tombamento $(T)$ de plântulas de feijoeiro, e da incidência (I) e severidade (S) da podridão do colo causada por Sclerotium rolfsii,após a incorporação ao solo de resíduos orgânicos em três cultivos

\begin{tabular}{|c|c|c|c|c|}
\hline \multicolumn{5}{|c|}{$1^{\circ}$ cultivo - Março/2005 } \\
\hline Tratamentos & $\mathrm{E}(\%)$ & $\mathrm{T}(\%)$ & $\mathrm{I}(\%)^{* *}$ & S (\%)** \\
\hline Testemunha (S. rolfsii) & $75,63 \mathrm{a}^{*}$ & $17,36 \mathrm{~b}$ & $74,16^{* * * *} \mathrm{a}$ & $28,44 \mathrm{a}$ \\
\hline Chorume de Suínos & $78,75 \mathrm{a}$ & $17,46 \mathrm{~b}$ & $75,75 \mathrm{a}$ & $24,31 \mathrm{a}$ \\
\hline Cama de Aviário & $78,75 \mathrm{a}$ & $7,14 \mathrm{a}$ & $47,17 \mathrm{~b}$ & $10,37 \mathrm{~b}$ \\
\hline Repolho triturado & $72,50 \mathrm{a}$ & $17,22 \mathrm{~b}$ & $72,10 \mathrm{a}$ & $22,96 \mathrm{a}$ \\
\hline C.V. & 17,72 & - & 1,37 & 11,71 \\
\hline \multicolumn{5}{|l|}{$2^{\circ}$ cultivo - Maio/2005 } \\
\hline Testemunha (S. rolfsii) & $83,13 \mathrm{a}$ & $5,64 \mathrm{~b}$ & $65,01 \mathrm{a}$ & $25,42 \mathrm{a}$ \\
\hline Chorume de Suínos & $77,81 \mathrm{a}$ & $4,14 \mathrm{~b}$ & $49,32 \mathrm{~b}$ & $13,04 \mathrm{~b}$ \\
\hline Cama de Aviário & $83,44 \mathrm{a}$ & $0,00 \mathrm{a}$ & $40,91 \mathrm{c}$ & $8,85 \mathrm{c}$ \\
\hline Repolho triturado & $81,88 \mathrm{a}$ & $3,44 \mathrm{~b}$ & $56,07 \mathrm{ab}$ & $20,05 \mathrm{a}$ \\
\hline C.V. & 21,56 & - & 3,54 & 10,58 \\
\hline \multicolumn{5}{|l|}{$3^{\circ}$ cultivo - Março/2006 } \\
\hline Testemunha (S. rolfsii) & $67,19 \mathrm{c}$ & $1,77 \mathrm{~b}$ & $46,68 \mathrm{a}$ & $13,17 \mathrm{a}$ \\
\hline Chorume de Suínos & $74,38 \mathrm{~b}$ & $0,30 \mathrm{a}$ & $28,13 \mathrm{~b}$ & $4,96 \mathrm{~b}$ \\
\hline Cama de Aviário & $78,44 \mathrm{a}$ & $0,43 \mathrm{a}$ & $25,48 \mathrm{~b}$ & $3,98 \mathrm{~b}$ \\
\hline Repolho triturado & $74,06 \mathrm{~b}$ & $1,23 \mathrm{~b}$ & $26,93 \mathrm{~b}$ & $5,43 \mathrm{~b}$ \\
\hline C.V. & 12,45 & - & 2,58 & 17,96 \\
\hline
\end{tabular}

Nota: *Médias seguidas pela mesma letra na coluna não diferem significativamente entre si pelo teste de Duncan, a $5 \%$ de probabilidade; ** Dados transformados em “ $(X+0,5)$ ”; *** dados originais.

traduzindo-se em um dos mecanismos de ação antagônica a fitopatógenos (MILLNER et al., 1982). Conclusões semelhantes também foram descritas por Morales et al. (2007) ao adicionarem doses de chorume de suínos ao solo, observando um aumento da atividade microbiana com o aumento das doses de chorume, sendo, portanto, a atividade microbiana apontado como o principal fator responsável pelo controle do fungo S.rolfsii. Além de o gás carbônico indicar uma maior atividade microbiana no solo, ele, por si só, também pode inibir a germinação do patógeno. Barreto et al. (1997) afirmam que o fungo $S$. rolfsii é altamente exigente em oxigênio e este fato limita a germinação de escleródios em solos pesados, e o desenvolvimento do patógeno só ocorre próximo à superfície. Porém, sua inabilidade para atingir as plantas se relaciona com a sua sensibilidade ao $\mathrm{CO}_{2}$, o qual é produto do crescimento microbiano e que se transforma em mecanismo de antagonismo (GRIFFIN, 1977). Tal fato foi constatado por Smith (1973) que em solos submetidos a ar contendo 0,1 ppm de etileno, escleródios de $S$. rolfsii permaneceram dormentes.

$\mathrm{O}$ aumento da atividade microbiana proporcionado pelos compostos orgânicos, no segundo e terceiro cultivo, pode estar relacionado ao menor número de escleródios encontrados nas parcelas (Tabela 2). No segundo cultivo, a testemunha e o tratamento RT apresentaram o maior número de escleródios, com 25,42 e 20,05 escleródios em $50 \mathrm{~g}$ de solo, respectivamente. Por outro 
lado, a CA apresentou o menor valor, com 8,85 escleródios em $50 \mathrm{~g}$ de solo. Assim, o efeito da CA na supressão das doenças fica comprovado, não somente pela redução da intensidade da doença, mas também pela redução do número de escleródios do patógeno. No terceiro cultivo não houve diferença entre as fontes de matéria orgânica, porém, os três tratamentos apresentaram menor número de escleródios do que a testemunha (Tabela 2). Entretanto, a atividade microbiana não é o único mecanismo atuando nesta relação patógeno-hospedeiro. Resíduos de brássicas comprovadamente liberam aldeídos, sulfetos e isotiocianatos, que inibem significativamente diversos fitopatógenos (GAMLIEL; STAPLETON 1993; SMOLINSKA et al., 1997; LODHA et al.,1997). Além disso, a liberação de ácidos graxos voláteis e ácido nitroso em $\mathrm{pH}$ ácido e amônia em $\mathrm{pH}$ alcalino, a partir de resíduos como o CS e, possivelmente, a CA, também são considerados tóxicos aos fitopatógenos (LAZAROVITZ, 2001; TENUTA; LAZAROVITS, 2002a; TENUTA et al., 2002b; CONN et al., 2005).

Com relação ao crescimento vegetativo, avaliado por meio da massa fresca, houve maior desenvolvimento vegetativo nas parcelas tratadas com $\mathrm{CA}$, com produção de 8,43 e 16,61 g planta ${ }^{-1}$ no segundo e terceiro cultivo, respectivamente (Tabela 2). Esses resultados podem ser correlacionados, em parte, à elevação das concentrações de fósforo (de 6,16 para 54,7 $\mathrm{mg} \mathrm{dm}^{-3}$ ) e potássio (de 0,25 para $1,00 \mathrm{mg} \mathrm{dm}^{-3}$ ) no solo, e ao nível de matéria orgânica (Tabela 2). Esses nutrientes também podem estar interferindo na relação patógeno-hospedeiro. $O$ fósforo aumenta a resistência das plantas às doenças por acelerar a maturação dos tecidos, auxiliando-a a escapar da infecção por patógenos que tem preferência por tecidos jovens (ZAMBOLIM; VENTURA, 1993).

Tabela 2. Avaliação de massa fresca (MF), teor de matéria orgânica (MO) do solo, atividade microbiana (AM) e número de escleródios, após o segundo e terceiro cultivos

\begin{tabular}{|c|c|c|c|c|}
\hline \multicolumn{5}{|c|}{$2^{\circ}$ cultivo - Maio/2005 } \\
\hline Tratamentos & $\begin{array}{l}\text { MF } \\
\left(\text { g planta }^{-1}\right)\end{array}$ & $\begin{array}{l}\mathrm{MO} \\
\left(\mathrm{mg} \mathrm{dm}^{-3}\right)\end{array}$ & $\begin{array}{l}\mathrm{AM}(\mathrm{mg} \mathrm{CO} \\
\left.100 \mathrm{~g} \mathrm{solo}^{-1}\right)\end{array}$ & $\begin{array}{l}\text { No Esc. (No } \\
\left.50 \mathrm{~g} \mathrm{solo}{ }^{-1}\right)\end{array}$ \\
\hline Testemunha (S. rolfsii) & $3,71 \mathrm{~b}$ & $78,44 \mathrm{~b}$ & $40,91 \mathrm{c}$ & $25,42 \mathrm{a}$ \\
\hline Chorume de Suínos & $6,47 \mathrm{ab}$ & $78,13 \mathrm{~b}$ & $56,07 \mathrm{ab}$ & $13,04 \mathrm{~b}$ \\
\hline Cama de Aviário & 8,43 a & $83,44 \mathrm{a}$ & $65,01 \mathrm{a}$ & $8,85 \mathrm{c}$ \\
\hline Repolho triturado & $4,31 \mathrm{~b}$ & $79,06 \mathrm{~b}$ & $49,32 \mathrm{~b}$ & $20,05 \mathrm{a}$ \\
\hline C.V. & 2,56 & 25,36 & 3,54 & 10,58 \\
\hline \multicolumn{5}{|l|}{ 30 cultivo - Março/2006 } \\
\hline Testemunha (S. rolfsii) & $7,54 \mathrm{~b}$ & $21,78 \mathrm{~b}$ & $13,62 \mathrm{~b}$ & $55,25 \mathrm{a}$ \\
\hline Chorume de Suínos & $7,56 \mathrm{~b}$ & $23,45 \mathrm{~b}$ & $28,47 \mathrm{a}$ & $23,50 \mathrm{~b}$ \\
\hline Cama de Aviário & $16,61 \mathrm{a}$ & $26,48 \mathrm{a}$ & $32,13 \mathrm{a}$ & $18,25 \mathrm{~b}$ \\
\hline Repolho triturado & $7,49 \mathrm{~b}$ & $23,45 \mathrm{~b}$ & $22,91 \mathrm{a}$ & $16,00 \mathrm{~b}$ \\
\hline C.V. & 6,78 & 2,59 & 8,96 & 22,36 \\
\hline
\end{tabular}

Nota: Médias seguidas pela mesma letra na coluna não diferem significativamente entre si pelo teste de Duncan a $5 \%$ de probabilidade. 


\section{Considerações Finais}

A incorporação de resíduos orgânicos reduziu o tombamento, incidência, severidade e número de escleródios do fungo $S$. rolfsii. $\mathrm{O}$ aumento da atividade microbiana do solo e a possível liberação de gases tóxicos são os prováveis mecanismos responsáveis pela redução da doença. A CA apresentou os melhores índices para os parâmetros avaliados, entretanto, mesmo assim, os danos provocados pelo patógeno foram extremamente elevados. Este fato pode ser explicado pelo alto potencial de inóculo do experimento, situação dificilmente encontrada em condições de cultivo no campo.

\section{Referências}

BARRETO, M. Doenças do amendoim (Arachi hypogaea L.). In: KIMATI, H.; AMORIM, L.; BERGAMIM FILHO, A.; CAMARGO, L.E.A.; REZENDE,J.A. M. (Ed.) Manual de Fitopatologia. Doenças de Plantas Cultivadas. 3.ed. São Paulo: Agronômica Ceres. 1997. p.63-77.

BIANCHINI, A.; MARINGONI, A. C.; CARNEIRO, S. M.T.P. G. Doenças do feijoeiro. In: KIMATI, H.; AMORIM, L.; BERGAMIN FILHO, A.; CAMARGO, L. E. A.; REZENDE, J. A. M. (Eds.). Manual de fitopatologia. Doença de Plantas Cultivadas. 3. ed. São Paulo: Agronômica Ceres, 1997. p. 376-399.

BUENO, C. J.; AMBRÓSIO, M. M. Q.; SOUZA, N. L.; CEREZINI, P. C. Controle de Fusarium oxysporum $f$.sp. lycopersici raça 2, Macrophomina phaseolina e Sclerotium rolfsii em microcosmo simulando solarização com prévia incorporação de couve (Brassicae oleracea var. acephala L.). Summa Phytopathologica, Botucatu, n. 3, v.30, p.356-363, 2004.

CONN, K. L.;TENUTA, M.; LAZAROVITS, G. Liquid swine manure can kill Verticillium dabliae microsclerotia in soil by volatile fatty acid, nitrous acid, and ammonia toxicity. Phytopathology, St. Paul, n. 1., v.95, p. 28-35, 2005.

GAMLIEL, A.; STAPLETON, J. J. Characterization of antifungal volatile compounds evolved from solarized soil amended with cabbage residues. Phytopathology, St. Paul, v.83, n.9, p.899-905, 1993.

GRIFFIN,D.M.Water potential and wood-decay fungi. Annual Review of Phytopathology, n.1, v.15, p.319-329, 1977.

GRISI, B. M. Método químico de medição da respiração edáfica: alguns aspectos técnicos. Ciência e Cultura, São Paulo, n. 1, v.30, p.82-88, 1978.

GHINI, R.; SCHOENMAKER,I. A. S.; BETTIOL,W. Solarização do solo e incorporação de fontes de matéria orgânica no controle de Pythium spp. Pesquisa Agropecuária Brasileira, Brasília, n.9, v.37, p.1253-1261, 2002. 
HOITINK, H. A. J.; FAHY, P. C. Basis for the control of soilborne plant pathogens with composts. Annual Review of Phytopathology, Palo Alto, v.24, p.93-114, 1986.

LAZAROVITS, G. Management of soil-borne plant pathogens with organic soil amendments: a disease control strategy salvaged from the past. Canadian Journal Plant Pathology, [S.I], v.23, p.1-7, 2001.

LODHA, S.; SHARMA, S. K.; AGGARWAL, R. K. Solarization and natural heating of irrigated soil amended with cruciferous residues for improved control of Macrophomina phaseoli. Plant Pathology, [S.I], v.46, p.186-190, 1997.

MILLNER, P. D.; LUMSDEM, R. D.; LEWIS, J. A. Controlling plant disease with sludge compost. Biocycle, Emmaus, n. 4, v.23, p.50-52, 1982.

MORALES, R. G.F.; SANTOS, I.; DANNER, M.A. Efeito do chorume líquido de suínos na podridão do colo e tombamento de plântulas de feijoeiro causadas por Sclerotium rolfsii. Fitopatologia Brasileira, Brasília, n. 5, v.32, p.429-433, 2007.

PAVAN, M. A.; MIYAZAWA, M. Análise química do solo: parâmetros para interpretação. IAPAR, 1991. 48 p. (Circular Técnica 91).

ROBBS, C.F. Bactérias como agentes de controle biológico de fitopatógenos. In: BETTIOL, W. Controle Biológico de Doenças de Plantas. Campinas: EMBRAPA/CNPDA, 1991. p.121-133.

RODRIGUEZ-KABANA, R.; CALVET,C.Capacidad del suelo para controlar enfermidades de origen edafico. Fitopatologia Brasileira, Brasília, n.2, v.19, p.129-138, 1994.

SCHOONHOVEN, A. VAN.; PASTOR-CORRALES, M. A. Standard System for the Evaluation of Bean Germplasm. CIAT, 1987.

SMITH,A.M. Ethylene as a cause of soil fungistasis. Nature, n. 5431, v.246, p.311-313, 1973.

SMOLINSKA, U.; MORRA, M. J.; KNUDSEN, G. R; BROWN, P. D. Toxicity of glucosinolate degradation products from Brassicas napus seed meal toward Aphanomyces euteiches f. Sp. Pisi. Phytopathology, St. Paul, n.1, v.87, p.77-82, 1997.

TENUTA, M.; LAZAROVITS, G. Ammonia and nitrous acid from nitrogenous amendments kill the microesclerotia of Verticillium dabliae. Phytopathology, St. Paul, n. 5, v.92, p.255-264, 2002a.

TENUTA, M.; CONN, K. L.; LAZAROVITS, G. Volatile fatty acids in liquid swine manure can kill microsclerotia of Verticillium dabliae. Phytopathology, St. Paul, n. 5, v.92, p.548-552, 2002b. 
ZAMBOLIM, L.; VENTURA, J. A. Resistência a doenças induzida pela nutrição mineral das plantas. In: LUZ, W. C.; FERNANDES, J. M.; PRESTES; A. M.; PICININI, E. C. (Ed.) Revisão Anual de Patologia de Plantas. Passo Fundo: RAPP, 1993. v.1, p. 275-318. 